\title{
Survey on the occurrence of dental trauma and preventive strategies among Brazilian professional soccer players
}

\author{
Marcos Britto CORREA ${ }^{1}$, Helena Silveira SCHUCH ${ }^{2}$, Kauê COLLARES ${ }^{2}$, Dione Dias TORRIANI ${ }^{3}$, \\ Pedro Curi HALLAL ${ }^{4}$, Flavio Fernando DEMARCO ${ }^{5}$
}

1- DDS, MS, PhD student, Post-graduation Program in Dentistry, Federal University of Pelotas, Pelotas, RS, Brazil.
2- Undergraduate student, Dental School, Federal University of Pelotas, Pelotas, RS, Brazil.
3- DDS, MS, PhD, Associate Professor, Department of Pediatric and Preventive Dentistry, Federal University of Pelotas, Pelotas, RS, Brazil.
4- DDS, MS, PhD, Adjunct Professor, Post-Graduation Program in Epidemiology, Federal University of Pelotas, Pelotas, RS, Brazil.
5- DDS, PhD, Associate Professor, Post-Graduation Program in Dentistry and Epidemiology, Federal University of Pelotas, Pelotas, RS, Brazil.

Corresponding address: Flávio Fernando Demarco - Universidade Federal de Pelotas - Faculdade de Odontologia - Rua Gonçalves Chaves, 457, $5^{\circ}$ - andar - Centro - 96015568 - Pelotas, RS - Brasil - Phone/fax: + 555332226690 - Ramal 135 - e-mail: flavio.demarco@pq.cnpq.br

Received: May 18, 2009 - Modification: October 18, 2009 - Accepted: February 16, 2010

\section{ABSTRACT}

\begin{abstract}
$\mathrm{O}$ bjectives: The aims of this study were to verify the occurrence of dental injuries in professional Brazilian soccer players, the level of knowledge of the teams' medical departments about mouthguards, and the conducts adopted in cases of dental trauma during the match. Material and Methods: Closed questionnaires were sent to the physicians in charge of the medical departments of the 40 teams enrolled in the first and second divisions of the Brazilian professional soccer league in 2007. The data obtained were subjected to descriptive analysis to determine absolute and relative frequencies of answers for each one of the questions. Results: Physicians from 38 (95\%) of the 40 teams in the first and second divisions answered the questionnaires and $71.1 \%$ reported the occurrence of some type of dental injury during soccer practice, dental fractures $(74.1 \%)$ and avulsions $(59.3 \%)$ being the most prevalent ones. Regarding emergency conducts, approximately $50 \%$ answered that a successful replantation could be obtained in periods from 6 to $24 \mathrm{~h}$ after injury, and $27.8 \%$ were not able to answer this question. Regarding mouthguard use, $48.6 \%$ of the physicians did not know about mouthguards, and only $21.6 \%$ usually recommended their use by the soccer players. Among the physicians who do not recommend the use of mouthguards, $50 \%$ justified that it was not necessary. Almost $50 \%$ of the medical departments do not have a dentist as part of the health professional staff. Conclusions: It was possible to conclude that dental injuries are common during professional soccer practice and that there is a lack of information in the medical departments related to the emergency conducts and prevention of dental trauma.
\end{abstract}

Key words: Athletic injuries. Soccer. Tooth injuries. Accident prevention. Mouthguards.

\section{INTRODUCTION}

Dental trauma is considered a major public oral health problem because the high prevalence and the impact caused in daily life ${ }^{21}$. The main causes of traumatic dental injuries are falls and collisions with people and objects, both factors are very present during sports practice $3,11,18,19$.

It has been shown that sports practice increases the risk of traumatic injuries such as dental trauma ${ }^{5}$. In the activities where contacts with athletes commonly occur, there is more susceptibility to dangerous falls or blows, and consequently, to dental injuries ${ }^{1,4,22}$. The modalities with increased risk are the contact sports such as wrestling and collective sports ${ }^{22}$.

Despite the common belief that soccer is not a violent sport, it presents a high risk of injuries to the athletes, including oral and craniofacial injuries ${ }^{4}$. In fact, during soccer matches the head is frequently used $^{2}$ and the impact between heads or head and elbow are the most prevalent causes of craniofacial injuries $^{12}$. In Europe, soccer is responsible for $50 \%$ of sports related to orofacial trauma, probably due 
to the high popularity of this sport in the continent ${ }^{20}$.

Several studies have demonstrated that oral health directly influences the players' performance. Dental trauma, which is a problem that can be prevented, should not affect the amateur and professional soccer practice. Several authors mentioned that mouthguard use could prevent the orofacial injuries in different kinds of sports ${ }^{5,17}$. In spite of this, mouthguard use is not common worldwide $^{15}$. Soccer is the most popular sport in Brazil, with thousand of players in the national, regional or local leagues. In Brazil, the use of mouthguards by the athletes is mandatory only in boxing practice. A literature review performed in indexed basis (PubMed, LILACS) showed that no study has investigated the occurrence and prevention of dental trauma in Brazilian professional soccer. Considering that an increased attention has been directed to Sports Dentistry, more investigations regarding dental trauma in sports should be performed.

The aim of this study was to perform a survey regarding the occurrence and prevention of dental trauma in professional soccer athletes by means of interviews with the medical departments of professional teams.

\section{MATERIAL AND METHODS}

\section{Ethical Aspects}

The study had the approval of the local Ethics Committee (Federal University of Pelotas, RS, Brazil). Each physician in charge for the medical department of the soccer teams invited to participate in the study received an informational document about the research and signed an informed consent form prior to enrollment in the study.

\section{Elaboration and delivery of the questionnaire}

For this study, a closed questionnaire (Tables 1-3) was prepared and sent to the head of the medical departments of the 40 teams that were enrolled in the first and second divisions of Brazilian professional league soccer in 2007 . To be included in the study, physicians needed to be working at the medical departments for at least 1 year. The questionnaire contained questions about the occurrence of traumatic dental injuries during the matches, the conducts adopted in cases of dental trauma, the knowledge of mouthguards, and the existence of a dentist as part of the team's health professional staff.

The questionnaires with the informational document were posted by regular mail including envelopes stamped to ensure the return of the answers. The questionnaire used was based on an instrument validated in previous study ${ }^{14}$. The data obtained was subjected to descriptive analysis to determine absolute and relative frequencies of answers and $95 \%$ confidence intervals for each one of the questions.

\section{RESULTS}

Physicians from 38 (95\%) of the 40 teams in the first and second divisions answered the questionnaires. All of them were working in the teams for a minimum of 1 year. Table 1 shows the

Table 1- Absolute and relative frequencies of dental trauma's occurrence-based questions in Brazilians soccer clubs, 2007

\begin{tabular}{llcc}
\hline Question & Answer & Absolut Frequency & $\%(95 \% \mathbf{C l})$ \\
\hline Have you ever seen a dental injury in a & 1. Yes & 27 & $71.1(54.1-84.6)$ \\
professional soccer player? & 2. No & 11 & $28.9(15.4-45.9)$ \\
If yes, what kind of dental injury? & 1. Avulsion & 16 & $59.3(44.3-73.6)$ \\
& 2. Dental Fracture & 20 & $74.1(59.6-86.1)$ \\
& 3. Dislocation & 9 & $33.3(20.9-49.3)$ \\
& 4. Others & 2 & $7.4(1.3-17.5)$ \\
How many times did you presence a & 1. Once & 5 & $18.5(6.3-38.1)$ \\
dental injury on players? & 2. Twice to 4 times & 14 & $51.9(31.9-71.3)$ \\
& 3. Up to 4 times & 8 & $29.6(13.7-50.2)$ \\
What's the players' position that they & 1. Goalkeeper & & \\
suffered dental trauma? & 2. Center Defender & 6 & $22.2(11.5-35.9)$ \\
& 3. Full-Back & 12 & $44.4(29.0-58.7)$ \\
& 4. Defensive midfielder & 2 & $7.4(2.2-19.2)$ \\
& 5. Offensive midfielder & 9 & $33.3(21.2-48.8)$ \\
& 6. Forward & 5 & $18.5(8.6-31.4)$
\end{tabular}


questions about dental trauma occurrence and the absolute and relative frequencies of the obtained data.

Regarding the occurrence of dental trauma in professional soccer players, $71.1 \%$ of the physicians saw at least once in their professional experiences, and $29.6 \%$ of them saw more than 4 times. The most common types of dental injuries observed were dental fractures $(74.1 \%)$ followed by avulsions (59.3\%). The players most affected by dental injuries were forwards (59.2\%) and center defenders (44.4\%).

When the physicians were questioned about conducts adopted in cases of tooth avulsion (Table $2), 94.6 \%$ answered that replantation of the avulsed tooth is possible, and $76.6 \%$ said that it is possible to obtain success if the replantation is done $6 \mathrm{~h}$ or more after the accident.

Regarding mouthguard use (Table 3 ), $48.6 \%$ of the physicians did not know any type of them, and

Table 2- Knowledge of heads of club's health departments about the conducts to be adopted in case of dental injuries during the game

\begin{tabular}{llcc}
\hline Question & Answer & Absolut Frequency & $\%(95 \% \mathrm{Cl})$ \\
\hline \multirow{2}{*}{$\begin{array}{l}\text { Do you know that is possible to replant an } \\
\text { avulsed tooth? }\end{array}$} & 1. Yes & 35 & $94.6(81.8-99.3)$ \\
& 2. No & 2 & $5.4(0.7-18.2)$ \\
In your opinion, within which period of time a tooth & 1. Up to 30 min & 0 & $0.0(0.0-9.5)$ \\
must be replanted? & 2. Up to 1 h & 3 & $8.3(1.7-21.9)$ \\
& 3. Up to 2 h & 4 & $11.1(3.0-25.4)$ \\
& 4. Up to 6 h & 7 & $19.4(8.0-35.1)$ \\
& 5. Up to 12 h & 3 & $8.3(1.7-21.9)$ \\
& 6. Up to 24 h & 8 & $21.1(9.8-38.2)$ \\
Are you aware that immediate action is essential & 7. Don't know & 10 & $27.8(13.8-44.1)$ \\
for a successful outcome? & 2. No & 34 & $97.1(85.1-99.9)$ \\
& & 1 & $2.9(0.1-14.9)$ \\
\hline Do you know a dentist emergency service? & 1. Yes & & $73.0(55.9-86.2)$ \\
\hline
\end{tabular}

Table 3- Knowledge about mouthguards of health departments' responsible

\begin{tabular}{llcc}
\hline Question & Answer & Absolut Frequency & $\%(95 \% \mathrm{Cl})$ \\
\hline Do you know a mouthguard? & 1. Yes & 19 & $51.4(34.4-68.1)$ \\
& 2. No & 18 & $48.6(31.9-65.6)$ \\
If yes, which kind of mouthguard? & 1. Stock & 3 & $15.8(4.2-33.7)$ \\
& 2. "Boil and Bite" & 11 & $57.9(38.8-77.6)$ \\
& 3. Custom-made & 13 & $68.4(46.0-83.4)$ \\
Do you recommend the wear of mouthguards & 1. Yes & 8 & $21.6(9.8-38.2)$ \\
by your team athletes? & 2. No & 25 & $67.6(50.2-82.0)$ \\
& 3. Only for somebody & 4 & $10.8(3.0-25.4)$ \\
If not, why? & & & \\
& 1. Communication & 0 & $0.0(0.0-12.8)$ \\
& 2. Breathe & 5 & $19.2(6.3-38.1)$ \\
& 3. Aesthetics & 2 & $7.7(0.9-24.3)$ \\
4he health department of your team has a & 1. Yes & 13 & $50.0(31.9-71.3)$ \\
dentistry department? & 2. No & 7 & $26.9(11.1-46.3)$
\end{tabular}


$67.6 \%$ had never recommended their use by the athletes. The lack of need was the most common reason $(50 \%)$ for physicians not recommending mouthguard use. Of the interviewed teams, 52.6\% have a dentistry department included in their medical departments.

\section{DISCUSSION}

Injuries are very common in sports, especially in those modalities involving more speed and close contact between athletes, which are more susceptible to facial and dental trauma ${ }^{14}$. Although soccer is not considered a dangerous activity ${ }^{4}$, $71.1 \%$ of the professional soccer team's physicians that took part in this study reported having observed dental injuries in soccer players during practice. This finding is in accordance with those of several authors that pointed soccer as a violent sport with high risk of injuries ${ }^{12,15,16,20}$. However, in this study, the time of experience of the physicians in the medical departments was not asked and dental trauma occurrence could be overestimated. The most frequent kinds of dental trauma reported in this study were dental fractures (74.1\%) and avulsions (59.3\%), which are considered the most serious types of dental trauma7. Such finding could be due to the fact that most severe injuries are easily perceived, while less severe injuries, like concussions or enamel fractures, could be underestimated.

In the present study, the players more frequently affected by dental trauma were forwards (59.1\%) and central defenders (44.4\%). In a recent research, authors watched 10 matches of the Premier League (England) and closely analyzed 18,000 play actions, concluding that when the ball is close to the goal, on defensive or offensive areas, its possession is most vigorously contested, increasing the injury potential during the match ${ }^{16}$.

Despite the fact that the majority of the interviewees answered that they were aware of the possibility of replanting avulsed teeth, and the need for immediate action for successful prognosis, $76.6 \%$ of them either reported that an avulsed tooth can be replanted up to $6 \mathrm{~h}$ after the accident or did not know the answer. The International Association of Dental Traumatology recommends that replantation must be done at most after 1 hour of the accident, or the long-term prognosis is not favorable ${ }^{7}$. The fact that only $52.6 \%$ of the teams have a dentist in their medical department can justify the lack of information about this subject.

An appropriate treatment plan after injury is important for successful tooth replantation ${ }^{7}$, and the knowledge of emergency services plays an important role in this aspect. In this study, $73.0 \%$ of the physicians interviewed knew a dental emergency service. Despite this, a considered number of Brazilian professional soccer teams (47.4\%) do not have a dentistry department, hindering the exchange between health specialties. As a consequence, the majority of the physicians did not have adequate information about the emergency conducts after a dental avulsion. This fact becomes more important if we consider that the physicians are the professionals that assist the athletes in the stadiums during the matches.

The mandatory wear of mouthguards in various sports like American football, rugby and boxing, makes it possible the prevention of dental injuries ${ }^{14,17}$. However, in soccer, mouthguard wear is not mandatory; consequently, the incidence of dental trauma is higher than other sports considered more violent, like martial arts ${ }^{10}$. These injuries can be prevented by protection of buccal region with mouthguards and by other strategies, like application of preventive programs in players focused in the adherence to the match rules and spirit of fair play ${ }^{8}$. Studies have demonstrated that most players do not have sufficient knowledge of prevention of dental injuries and mouthguards ${ }^{22}$. Forty-eight percent of the physicians in charge for medical departments in soccer teams in this study had no knowledge of mouthguards, and this could impair the possibilities of dental trauma prevention.

Only $21.6 \%$ of the physicians interviewed recommended the regular use of mouthguards for the players. This low rate could be attributed to the lack of information regarding to this protective device. In fact, the most frequently mentioned reason for not indicating mouthguards for the players was the belief that they are not necessary (50.0\%). Other studies have mentioned difficult to communication and breathe, and discomfort as the main reasons for athletes avoiding mouthguards use $^{5,17}$.

Different types of mouthguards are available and provide a sufficient level of protection to soccer players. Custom-made mouthguards are considered as the best option because they offer better protection with more comfort, without causing difficulties to breathe or talk during the match $^{6,13}$. The majority of health professionals that knew mouthguards in this study described the custom-made ones (68.4\%). It is evident that a low proportion of Brazilian professional soccer players are wearing mouthguards during the matches and training activities. If this situation is present in the elite soccer, one can assume that a worse situation could be expected in the other minor leagues.

There is a long history of mouthguard use in sports. Mouthguards started being used in professional boxing in the early 1920's and become mandatory in American football in 1962, being currently requested in four sport modalities 
in USA (ice hockey, lacrosse, field hockey and football). However, the American Dental Association recommends the use of mouthguards in 29 sports/ exercise activities. Also, meta-analyses have demonstrated that the risk of an orofacial sports injury was 1.6-1.9 times higher when a mouthguard was not worn'.

To improve the situation observed in this study, the inclusion of a dentist as a member of medical departments of the Brazilian soccer professional teams should be mandatory, not only for prevention and treatment of dental injuries, but also for maintenance of players' oral health. In this context, Sports Dentistry ${ }^{17}$ emerges as a specialty to supply these and other future demands that appear in the universe of the professional elite soccer. Worldwide, Sports Dentistry has gained an increased interest and Brazilian dental professionals should be aware of this new area of clinical practice. Also, the Federations or Confederations responsible for sports practice regulation must understand that dentistry is an important part in the context of systemic health and different dental problems can impair the performance of professional players.

\section{CONCLUSIONS}

It can be concluded that dental injuries are common during Brazilian professional soccer practice and that there is a lack of information in the medical departments related to the emergency conducts and prevention of dental trauma. Strategies should be developed to improve the knowledge of teams' health professionals about the prevention and management of dental injuries. Other studies should be performed to stimulate the development of sports dentistry in Brazil.

\section{REFERENCES}

1- American Dental Association. Council on Access, Prevention and Interprofessional Relations. ADA Council on Scientific Affairs. Using mouthguards to reduce the incidence and severity of sports-related oral injuries. J Am Dent Assoc. 2006;137:1712-20.

2- Andersen TE, Arnason A, Engebretsen L, Bahr R. Mechanisms of head injuries on elite football. Br J Sports Med. 2004;38:690-6. 3- Celenk S, Sezgin B, Ayna B, Atakul F. Causes of dental fractures in early permanent dentition: a retrospective study. J Endod. 2002;28:208-10.

4- Cerulli G, Carboni A, Mercurio A, Perugini M, Becelli R. Soccer-related craniomaxillofacial injuries. J Craniofac Surg. 2002;13:627-30.
5- Çetinbaş T, Sönmez H. Mouthguard utilization rates during sport activities in Ankara, Turkey. Dent Traumatol. 2006;22:127-32.

6- Eroğlu E, Diljin KA, Lütfi BM. Elite tae kwon do athletes' satisfaction with custom-made mouthguards. Dent Traumatol. 2006;22:193-7.

7- Flores MT, Anderson L, Andreasen JO, Bakland LK, Malmgren $B$, Barnett $F$, et al. Guidelines for the management of traumatic dental injuries. II. Avulsion of permanent teeth. Dent Traumatol. 2007;23:130-6.

8- Junge A, Rösch D, Peterson L, Graf-Baumann T, Dvorak J. Prevention of soccer injuries: a prospective intervention study in youth amateur players. Am J Sports Med. 2002;30:652-9.

9- Knapik JJ, Marshall SW, Lee RB, Darakjy SS, Jones SB, Mitchener TA, et al. Mouthguards in sport activities: history, physical properties and injury prevention effectiveness. Sports Med. 2007;37:117-44.

10- Levin L, Friedlander LD, Geiger SB. Dental and oral trauma and mouthguard use during sport activities in Israel. Dent Traumatol. 2003;19:237-42.

11- Marcenes W, Al Beiruti N, Tayfour D, Issa S. Epidemiology of traumatic injuries to the permanent incisors of 9-12-yearold schoolchildren in Damascus, Syria. Endod Dent Traumatol. 1999; 15:117-23.

12- Papakosta V, Koumoura F, Mourouzis C. Maxillofacial injuries sustained during soccer: incidence, severity and risk factors. Dent Traumatol. 2008;24:193-6.

13- Patrick DG, van Noort R, Found MS. Scale of protection and the various types of sports mouthguard. $\mathrm{Br}$ J Sports Med. 2005;39:278-81.

14- Perunski S, Lang B, Pohl Y, Filippi A. Level of information concerning dental injuries and their prevention in Swiss basketball - a survey among players and coaches. Dent Traumatol. 2005;21:195-200.

15- Pribble JM, Maio RF, Freed GL. Parental perceptions regarding mandatory mouthguard use in competitive youth soccer. Inj Prev. 2004; 10:159-62.

16- Rahnama N, Reilly $T$, Lees A. Injury risk associated with playing actions during competitive soccer. $\mathrm{Br}$ J Sports Med. 2002;36:354-9.

17- Ranalli DN. Sports dentistry and dental traumatology. Dent Traumatol. 2002;18:231-6.

18- Scariot R, Oliveira IA, Passeri LA, Rebellato NL, Müller PR. Maxillofacial injuries in a group of Brazilian subjects under 18 years of age. J Appl Oral Sci. 2009;17:195-8.

19- Tapias MA, Jiménez-Garcia R, Lamas F, Gil AA. Prevalence of traumatic crown fractures to permanent incisors in a childhood population: Móstoles, Spain. Dent Traumatol. 2003;19:119-22.

20- Tozoglu S, Tozoglu U. A one-year review of craniofacial injuries in amateur soccer players. J Craniofac Surg. 2006;17:825-7.

21- Traebert J, Peres MA, Blank V, Böel Rda S, Pietruza JA. Prevalence of traumatic dental injury and associated factors among 12-year-old school children in Florianópolis, Brazil. Dent Traumatol. 2003;19:15-8.

22- Yamada T, Sawaki Y, Tomida S, Tohnai I, Ueda M. Oral injury and mouthguard usage by athletes in Japan. Endod Dent Traumatol. 1998;14:84-7. 